\title{
Electrical conductivity of solutions of lithium bis(fluorosulfonyl)imide in mixed organic solvents and multi-objective solvent optimization for lithium-ion batteries
}

\author{
Johannes Neuhaus, Esther Forte, Erik von Harbou ${ }^{1}$, Hans Hasse \\ Laboratory of Engineering Thermodynamics (LTD), University of Kaiserslautern, \\ Erwin-Schrödinger Str. 44, D-67663 Kaiserslautern, Germany
}

\begin{abstract}
Lithium bis(fluorosulfonyl)imide (LiFSI) is an interesting novel electrolyte for lithium-ion batteries. In the present work, the electrical conductivity of solutions of LiFSI in binary and ternary mixtures of the solvents dimethyl carbonate (DMC), ethylene carbonate (EC) and propylene carbonate (PC) was studied experimentally for concentrations of LiFSI up to $0.2 \mathrm{~mol} \mathrm{~mol}^{-1}$ at ambient pressure and temperatures between 293 and $333 \mathrm{~K}$. Information on the electrical conductivity of LiFSI in the pure solvents DMC, EC, and PC is available from previous work. An empirical correlation of the electrical conductivity $\sigma$ of the studied solutions of LiFSI is presented that describes the dependence of $\sigma$ on the LiFSI concentration, the solvent composition, and the temperature. Based on this correlation, a multi-objective optimization of the LiFSI concentration and the solvent composition was carried out with two conflicting objectives relevant to the performance and costs of batteries: maximizing electrical conductivity and minimizing the amount of the expensive electrolyte LiFSI. The solubility limits of the ternary solvent system DMC-EC-PC were included in the optimization as
\end{abstract}


constraints. The multi-objective optimization applied here, is shown to be useful for obtaining a rational basis for decision-making in the design of electrolyte solutions for batteries.

Keywords: lithium bis(fluorosulfonyl)imide, lithium-ion battery, multi-objective optimization, Pareto, electrolyte solution

\section{Introduction}

Lithium-ion batteries $(\mathrm{LiB})$ are well established for the safe and efficient storage of electrical energy and there is a continuously growing demand for both smaller and more powerful devices [1-3]. Advanced electrolyte solutions can contribute to the progress in the field of LiB-technology [4-11].

A promising new electrolyte for LiB is lithium bis(fluorosulfonyl)imide (LiFSI). LiFSI has a higher electrical conductivity in organic solvents that are commonly used in LiB than the benchmark electrolyte $\mathrm{LiPF}_{6}$ [12]. Further, LiFSI has other advantages like a better stability regarding hydrolysis and lower aluminium corrosion $[13-18]$.

Commonly used solvents in LiB are dimethyl carbonate (DMC), ethylene carbonate (EC), and propylene carbonate (PC) [19]. We have recently presented a comprehensive study on physico-chemical properties of LiFSI in these solvents, which includes data on the electrical conductivity [12]. However in that study,

\footnotetext{
${ }^{1}$ Author to whom correspondence should be addressed. Electronic mail: erik.vonharbou@mv.uni-kl.de. Telephone: +49-631/205-5585. Fax: +49-631/205-3835.
} 
only pure solvents were investigated. For solutions of LiFSI in solvent mixtures, up to now, only spotty data is available. Tab. 1 gives an overview of literature data on physico-chemical properties of solutions of LiFSI in solvent mixtures.

Table 1: Overview of literature data on physico-chemical properties of solutions of LiFSI in organic solvents mixtures.

\begin{tabular}{ccccc}
\hline \hline Solvent (mixture) & $c_{\text {LifSI }} / \mathrm{M}$ & $T / \mathrm{K}$ & Properties & Reference \\
\hline DEC-EC $(7: 3)$ & 1.0 & $253-293$ & $\sigma, \eta$ & Takekawa et al. [20] \\
DMC-EC $(1: 1,9: 1)$ & 1.0 & 298 & $\sigma, \eta$ & Uchida and Ishikawa [21] \\
DMC-EC $(1: 1)$ & $0.6-5.3$ & 303 & $\sigma, \eta, \rho$ & Wang et al. [18] \\
DMC-EMC $(3: 7)$ & 1.0 & $223-323$ & $\sigma$ & Li et al. [22] \\
EMC-EC $(7: 3)$ & 1.0 & $253-333$ & $\sigma, \eta$ & Han et al. [13] \\
DMC-EMC-EC $(2: 3: 5)$ & 1.0 & $253-323$ & $\sigma$ & Li et al. [22] \\
\hline$\sigma$ electrical conductivity, $\rho$ density, $\eta$ shear viscosity; ${ }^{*}:$ volume ratio. \\
Abbr.: DEC: diethyl carbonate; DMC: dimethyl carbonate; \\
EC: ethylene carbonate; EMC: ethyl-methyl carbonate. \\
\hline \hline
\end{tabular}

In the present work a systematic experimental study on the electrical conductivity of solutions of LiFSI in binary and ternary solvent mixtures of DMC, EC, and PC, was carried out for concentrations of LiFSI up to $0.2 \mathrm{~mol} \mathrm{~mol}^{-1}$ at ambient pressure and temperatures between 293 and $333 \mathrm{~K}$. Based on the new data and that from our previous work [12], an empirical correlation of the dependence of the electrical conductivity on the temperature and composition of the electrolyte solution was developed.

The identification of an optimal composition of the electrolyte solution for $\mathrm{LiB}$ is a challenging task. The electrical conductivity and the costs of the electrolyte solution depend strongly on the concentration of the conductive salt (LiFSI). Furthermore, solid precipitation may occur at temperatures relevant for technical applications. Hence, there are multiple goals, which are conflict- 
ing. We solve this multi-objective optimization problem by the calculation of so-called Pareto sets. A Pareto set is defined as a set comprising all solutions in which an improvement in any objective can only be achieved by accepting a decline in at least one other objective [23-26]. The conflicting objectives that are considered here are the electrical conductivity that should be high and the LiFSI concentration that should be low, as LiFSI is expensive. The solubility limit of the ternary solvent system DMC-EC-PC is included in the optimization as a constraint. The liquid phase non-idealities are described by means of the NRTL model [27]. The NRTL model was parametrized in this work using experimental data of the solid-liquid equilibria of the binary solvent systems DMC-EC, DMC-PC, and EC-PC, reported by Ding et al. [28].

The multi-objective optimization strategy applied here can be extended to include more objectives and constraints. The present study provides an example that shows that multi-objective optimization is a powerful tool for optimizing battery electrolyte solutions.

\section{Electrical conductivity}

\subsection{Chemicals and sample preparation}

Lithium bis(fluorosulfonyl)imide (LiFSI, $\geq 0.999 \mathrm{~g} \mathrm{~g}^{-1}$ ) was supplied by Budan Process UG. Dimethyl carbonate (anhydrous, $\geq 0.999 \mathrm{~g} \mathrm{~g}^{-1}$ ), ethylene carbonate (anhydrous, $0.99 \mathrm{~g} \mathrm{~g}^{-1}$ ), and propylene carbonate (anhydrous, $0.997 \mathrm{~g} \mathrm{~g}^{-1}$ ) were purchased from Sigma Aldrich. All chemicals were used as 
received. The water content of the pure components was determined by coulometric Karl-Fischer titration (Metrohm $831 \mathrm{KF}$ coulometer) and were found to be below $50 \cdot 10^{-6} \mathrm{~g} \mathrm{~g}^{-1}$ for all solvents, and below $30 \cdot 10^{-6} \mathrm{~g} \mathrm{~g}^{-1}$ for LiFSI. All chemicals were handled in an inert gas glove box (GS Glovebox Technik) that maintained an nitrogen atmosphere with a water content of less than $2 \cdot 10^{-6} \mathrm{~g} \mathrm{~g}^{-1}$. A laboratory balance (Mettler-Toledo AG204) with an accuracy of $\pm 0.0001 \mathrm{~g}$ according to the calibration protocol was used for the gravimetrical sample preparation. The total mass of each prepared sample was larger than $30 \mathrm{~g}$. The samples were hermetically sealed in $40 \mathrm{ml}$ glass vials. The uncertainty of the mass fraction of the components is estimated to be $\pm 0.00015 \mathrm{~g} \mathrm{~g}^{-1}$. Some relevant physico-chemical properties of the employed solvents and LiFSI are shown in Tab. 2, wherein $M$ is the molar mass, $T_{\mathrm{nmp}}$ and $T_{\mathrm{nbp}}$ are the normal melting point and the normal boiling point, respectively, $\rho$ is the density, $\eta$ is the shear viscosity, $D$ is the self-diffusion coefficient and $\epsilon$ is the dielectric constant.

\subsection{Method of Measurement}

A conductivity meter (Mettler-Toledo Seven Multi equipped with an inLab 720 probe) was used for the measurements of the electrical conductivity. The measurements were carried out at ambient pressure. The conductivity meter was calibrated at $298.15 \mathrm{~K}$ using aqueous solutions of $\mathrm{NaCl}$ with a maximum concentration of $\mathrm{NaCl}$ of $0.3 \mathrm{~mol}^{-1}$. The reference data were taken from [38]. The maximum relative deviation of an individual result from the calibration 
Table 2: Overview of pure component physico-chemical properties of substances that were used in the present work. The numbers for $\rho, \eta$, and $\epsilon$ for DMC, EC, and PC refer to the liquid state at $313.15 \mathrm{~K}$ and ambient pressure.

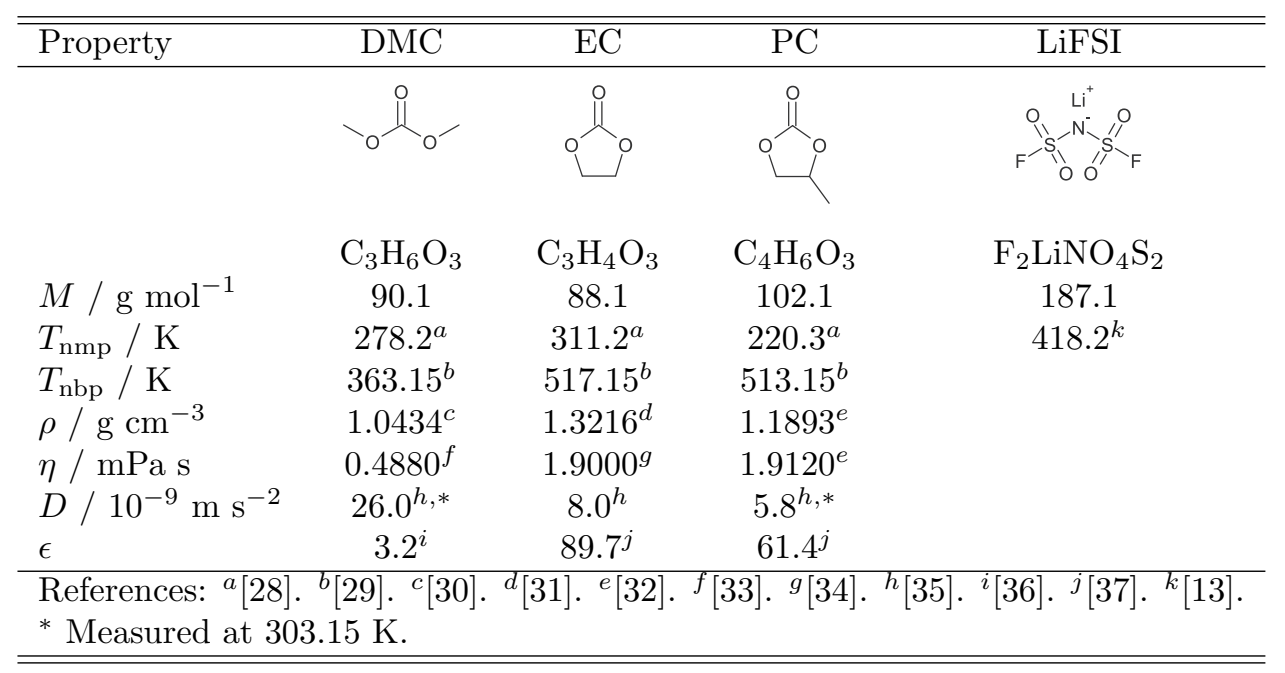

curve was $0.8 \%$. That number is taken for the uncertainty of the measurement of the electrical conductivity. The temperature was controlled using a thermostat (Julabo F32 HE) and measured with the built-in thermometer provided by the instrument's supplier which was calibrated in our laboratory using a certified standard. The uncertainty of the temperature measurement is $\pm 0.1 \mathrm{~K}$. Before and after each set of measurements the apparatus was cleaned with toluene, water, and ethanol and flushed with dry nitrogen.

\subsection{Correlation}

For correlating the electrical conductivity of the studied electrolyte solutions, a Taylor-series type expression shown in Eq. (1) was found to be suitable.

$$
\left(\frac{\sigma}{\mathrm{mS} \mathrm{cm}^{-1}}\right)=\sum_{k=1}^{m} \tilde{x_{k}} \sigma_{\mathrm{LiFSI}, k}+\sum_{k=1}^{m} \sum_{j \neq k}^{n} \tilde{x}_{k} \tilde{x}_{j} C_{k, j} \quad k, j=(\mathrm{DMC}, \mathrm{EC}, \mathrm{PC})
$$


The first term describes the normalized sum of the electrical conductivity of solutions of LiFSI in the pure solvents, wherein $\tilde{x}_{k}$ is the normalized mole fraction of solvent $k$ that are defined in Eq. (2).

$$
\tilde{x}_{k}=\frac{n_{k}}{n_{\mathrm{DMC}}+n_{\mathrm{EC}}+n_{\mathrm{PC}}}
$$

where $n_{i}$ is the mole number of substance $i$.

The description of the electrical conductivity of solutions of LiFSI in the pure solvent $k \sigma_{\mathrm{LiFSI}, k}$ is adapted from our previous work and shown in Eq. (3).

$$
\left.\left(\frac{\sigma_{\mathrm{LiFSI}, k}}{\mathrm{mS} \mathrm{cm}}\right)^{-1}\right)=A_{0, k}+A_{1, k} X_{\mathrm{LiFSI}}+A_{2, k} X_{\mathrm{LiFSI}}^{2}+A_{3, k} X_{\mathrm{LiFSI}}^{3}+A_{4, k} X_{\mathrm{LiFSI}}^{4}
$$

where $X_{\mathrm{LiFSI}}$ is the apparent molar loading of the solvent (mixture) with LiFSI.

$$
X_{\mathrm{LiFSI}}=\frac{n_{\mathrm{LiFSI}}}{n_{\mathrm{DMC}}+n_{\mathrm{EC}}+n_{\mathrm{PC}}}
$$

The $A_{i, k}$ are empirical temperature-dependent functions

$$
A_{i, k}=a_{i, k}+b_{i, k}\left(\frac{T}{T_{0}}\right)
$$

with $i=(0, \ldots, 4) . T$ is the absolute temperature and $T_{0}=273.15 \mathrm{~K}$.

$a_{i, k}$ and $b_{i, k}$ are adjustable parameters reported in our previous work [12].

The second term of Eq. (1) describes non-linear effects in the mixed solvents, wherein the $C_{k, j}$ are the binary solvent mixture interaction parameters that 
depend on the LiFSI concentration as shown in Eq. (6):

$$
\frac{C_{k, j}}{\mathrm{mS} \mathrm{cm}}{ }^{-1}=c_{k, j, 0} X_{\mathrm{LiFSI}}+c_{k, j, 1} X_{\mathrm{LiFSI}}^{2}+c_{k, j, 2} X_{\mathrm{LiFSI}}^{3}
$$

wherein the parameters $c_{k, j, 0}$ depend on temperature as given in Eq. (7).

$$
c_{k, j, 0}=c_{k, j, 01}+c_{k, j, 02}\left(\frac{T}{T_{0}}\right)
$$

The parameters $c_{k, j, 1}$ and $c_{k, j, 2}$ do not depend on temperature. The $c_{k, j, i}$ with $i=(01,02,1,2)$ are adjustable parameters.

The adjustable parameters in the correlations presented above were determined from a fit to the corresponding experimental data $\sigma_{i}^{\exp }$. The sum of the squared relative errors between the experimental data and the correlation $e_{j}=\left(\sigma_{j}^{\text {corr }}-\sigma_{i}^{\exp }\right) / \sigma_{i}^{\exp }$ was employed as objective function. The optimization was carried out in Matlab 2016b using the solver lsqnonlin.

\subsection{Results}

The experimental data, that were obtained in the present work for the electrical conductivity of solutions of LiFSI in binary and ternary solvents mixtures of DMC, EC, and PC are reported in the Tables 3 and 4 . The parameters of the correlation are reported in Tab. 5. For EC-PC only one parameter $\left(b_{\mathrm{EC}, \mathrm{PC}, 01}\right)$ is used, all other parameters from Eq. (6) were not significant and therefore set to zero. An additional parameter for the ternary solvent mixture DMC-EC-PC was not required. 


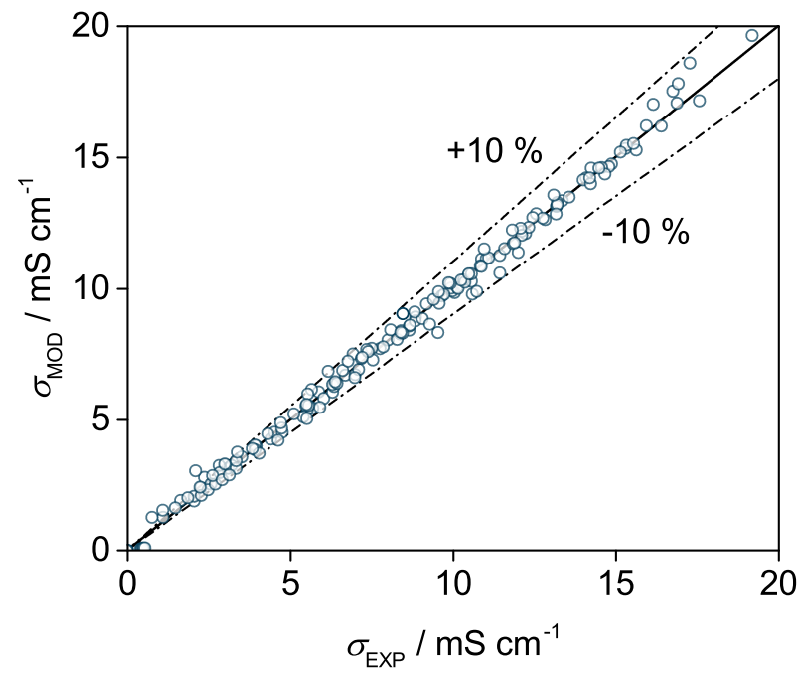

Figure 1: Parity plot of the electrical conductivity of solutions of LiFSI in the pure solvents (DMC, EC, PC), binary (DMC-EC, DMC-PC, EC-PC), and ternary solvent mixtures (DMC-EC-PC) at temperatures between 273.15 and $333.15 \mathrm{~K}$ and mole fractions of LiFSI up to $0.2 \mathrm{~mol} \mathrm{~mol}{ }^{-1}$. Experimental data from the present work and from a previous study on the pure solvents [12] are compared to results from the correlation developed in the present work.

Fig. 1 shows a parity plot in which the experimental results for the electrical conductivity are compared with the results from the correlation. The data for the pure solvents from our previous study [12] is included. The mean absolute deviation is $0.2 \mathrm{mS} \mathrm{cm}{ }^{-1}$, the relative deviations are below $10 \%$ except for small values of $\sigma$. The deviations mainly result from the scattering of the experimental data. No systematic trends were found. 
An example of results from the correlation is presented in Fig. 2, it shows the electrical conductivity of solutions of LiFSI in DMC-EC-PC at $298 \mathrm{~K}$ and a constant mole fraction of LiFSI of $0.05 \mathrm{~mol} \mathrm{~mol}^{-1}$ as a function of the normalized mole fractions of the solvents. A triangular diagram is used for representing the solvent composition in which the pure solvents are found on the corners, binary solvent mixtures on the sides, and ternary mixtures inside the triangle. The electrical conductivities in the solutions of LiFSI in the pure solvents (DMC, EC, PC) are $(4.1,6.4,6.1) \mathrm{mS} \mathrm{cm}^{-1}$. For the binary solvent mixture EC-PC, the electrical conductivity is a linear function of the solvent composition. This is not astonishing as EC and PC are similar (see Tab. 2).

In binary solutions of DMC-EC and DMC-PC, the electrical conductivity shows a strong non-linear dependence on the solvent composition. In the solvent mixture, an important increase of the electrical conductivity compared to that of the pure solvents is observed, with maxima $(11.1,9.7) \mathrm{mS} \mathrm{cm}^{-1}$ at a normalized mole fraction of DMC of about $0.45 \mathrm{~mol} \mathrm{~mol}^{-1}$. The positive co-operative effects in these binary mixtures are related to the different structure of the two solvents. Planar carbonates like DMC have low viscosities, but the drawback of low relative permittivities. In contrast, cyclic carbonates like EC and PC have higher viscosity but much higher relative permittivities (see Tab. 2). When mixed, the beneficial properties of both groups, low viscosity and high relative permittivity, are combined synergistically, resulting in the observed maxima in the electrical conductivity. This finding is in line with 


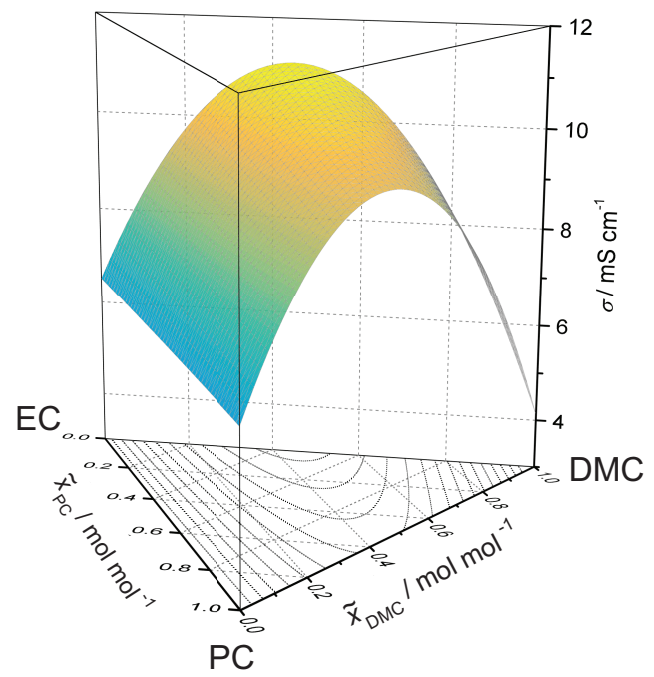

Figure 2: Results from the correlation of experimental data developed in the present work. Electrical conductivity of solutions of LiFSI in mixtures of DMC-EC-PC at $298 \mathrm{~K}$ and a constant mole fraction of LiFSI of $0.05 \mathrm{~mol} \mathrm{~mol}^{-1}$.

findings in solutions of $\mathrm{LiPF}_{6}$ and $\mathrm{LiClO}_{4}$ in carbonate solvent mixtures [39, 40].

For a fixed solvent composition, an increasing concentration of LiFSI firstly results in an increase of the electrical conductivity until a maximum is reached. A further increase of the LiFSI concentration results in a decrease of the electrical conductivity. This behavior is well-known and related to the interplay of the number of ions and their mobility.

Hence, for each solvent composition, a salt concentration can be found for which the electrical conductivity is maximal. This was done for solutions of LiFSI in mixtures of DMC, EC, and PC at $298 \mathrm{~K}$. The result is presented in Fig. 3. In panel a) of Fig. 3, the maximal electrical conductivity is shown 
as a function of the solvent composition, in panel b) the corresponding LiFSI concentration is shown. Again, strong synergistic effects are observed in the mixtures DMC-EC and DMC-PC. The overall maximum of the electrical conductivity $\left(12.8 \mathrm{mS} \mathrm{cm}^{-1}\right)$ is found in the binary solvent mixture DMC-EC. The corresponding number of the solvent mixture DMC-PC is $11.7 \mathrm{mS} \mathrm{cm}^{-1}$. In both systems the maxima are observed for a normalized mole fraction of DMC of about $0.45 \mathrm{~mol} \mathrm{~mol}^{-1}$. For ternary solvent mixtures no unexpected effects are observed. It is interesting to see that the maximal electrical conductivity does not correspond to a maximum in the LiFSI concentration (compare panels a) and b) of Fig. 3). On the contrary, for the solvent mixture DMC-EC, the maximal electrical conductivity is found for a remarkably low salt concentration. 

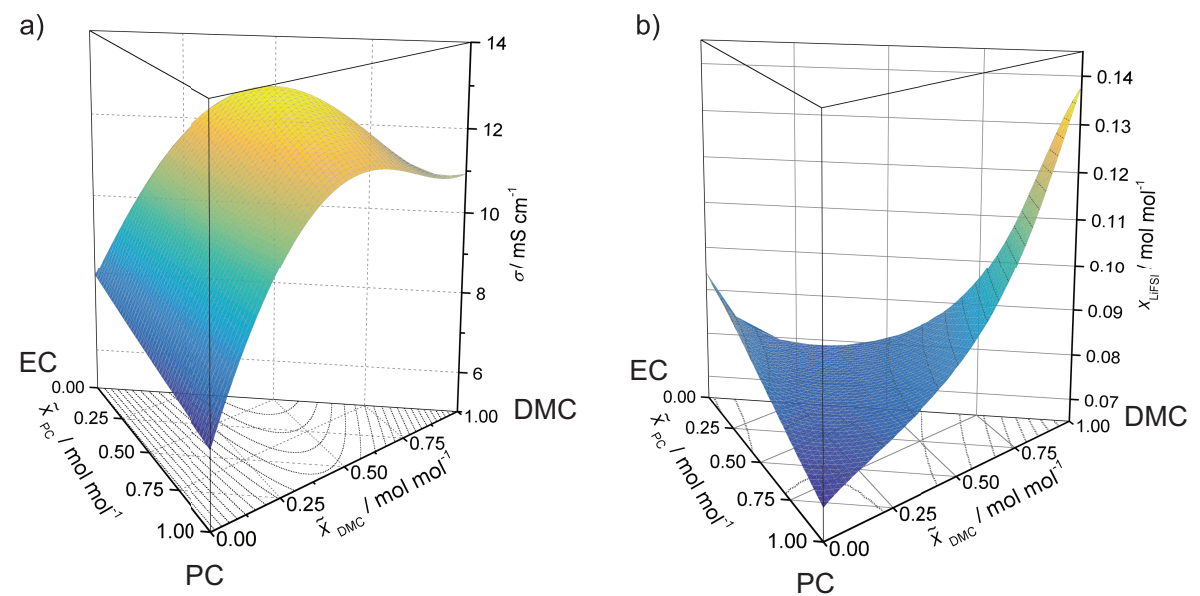

Figure 3: Results from the correlation of experimental data developed in the present work. Electrical conductivity of solutions of LiFSI in mixtures of DMC-EC-PC at $298 \mathrm{~K}$ : for a given solvent composition, there is a certain concentration of LiFSI for which the electrical conductivity is maximal. Panel a) shows the maximal electrical conductivity, panel b) the corresponding concentration of LiFSI. 
Table 3: Electrical conductivity in the systems LiFSI-DMC-EC, LiFSI-DMC-PC, and LiFSI-EC-PC. Experimental results from the present work.

\begin{tabular}{c|ccc}
\hline \hline \multicolumn{4}{c}{ LiFSI-DMC-EC } \\
\hline$T / \mathrm{K}$ & $x_{\text {LiFSI }} / \mathrm{mol} \mathrm{mol}^{-1}$ & $x_{\mathrm{DMC}} / \mathrm{mol} \mathrm{mol}^{-1}$ & $\sigma / \mathrm{mS} \mathrm{cm}^{-1}$ \\
\hline \multirow{3}{*}{293.15} & 0.0617 & 0.4879 & 10.57 \\
& 0.1094 & 0.4212 & 10.26 \\
& 0.1714 & 0.3801 & 7.49 \\
\hline \multirow{3}{*}{313.15} & 0.0617 & 0.4879 & 14.21 \\
& 0.1094 & 0.4212 & 14.74 \\
& 0.1714 & 0.3801 & 12.08 \\
\hline \multirow{3}{*}{333.15} & 0.0617 & 0.4879 & 17.51 \\
& 0.1094 & 0.4212 & 19.61 \\
& 0.1714 & 0.3801 & 17.15 \\
\hline \hline
\end{tabular}

\begin{tabular}{c|ccc}
\hline \hline \multicolumn{4}{c}{ LiFSI-DMC-PC } \\
\hline$T / \mathrm{K}$ & $x_{\text {LiFSI }} / \mathrm{mol} \mathrm{mol}^{-1}$ & $x_{\mathrm{DMC}} / \mathrm{mol} \mathrm{mol}^{-1}$ & $\sigma / \mathrm{mS} \mathrm{cm}^{-1}$ \\
\hline \multirow{3}{*}{293.15} & 0.0724 & 0.4591 & 9.77 \\
& 0.1325 & 0.4341 & 8.56 \\
& 0.1761 & 0.4095 & 6.15 \\
\hline \multirow{3}{*}{313.15} & 0.0724 & 0.4591 & 13.33 \\
& 0.1325 & 0.4341 & 12.67 \\
& 0.1761 & 0.4095 & 9.98 \\
\hline \multirow{3}{*}{333.15} & 0.0724 & 0.4591 & 17.01 \\
& 0.1325 & 0.4341 & 17.06 \\
& 0.1761 & 0.4095 & 14.35 \\
\hline \hline
\end{tabular}

\begin{tabular}{c|ccc}
\hline \hline \multicolumn{3}{c}{ LiFSI-EC-PC } \\
\hline$T / \mathrm{K}$ & $x_{\text {LiFSI }} / \mathrm{mol} \mathrm{mol}^{-1}$ & $x_{\mathrm{EC}} / \mathrm{mol} \mathrm{mol}^{-1}$ & $\sigma / \mathrm{mS} \mathrm{cm}^{-1}$ \\
\hline \multirow{3}{*}{293.15} & 0.0750 & 0.4662 & 6.39 \\
& 0.1240 & 0.4380 & 5.10 \\
& 0.1719 & 0.4216 & 3.25 \\
\hline \multirow{3}{*}{313.15} & 0.0750 & 0.4662 & 9.76 \\
& 0.1240 & 0.4380 & 8.62 \\
& 0.1719 & 0.4216 & 6.26 \\
\hline \multirow{3}{*}{333.15} & 0.0750 & 0.4662 & 13.55 \\
& 0.1240 & 0.4380 & 12.82 \\
& 0.1719 & 0.4216 & 10.20 \\
\hline \hline
\end{tabular}


Table 4: Electrical conductivity in the system LiFSI-DMC-EC-PC. Experimental results from the present work.

\begin{tabular}{c|cccc}
\hline \hline$T / \mathrm{K}$ & $x_{\mathrm{LiFSI}} / \mathrm{mol} \mathrm{mol}^{-1}$ & $x_{\mathrm{DMC}} / \mathrm{mol} \mathrm{mol}^{-1}$ & $x_{\mathrm{EC}} / \mathrm{mol} \mathrm{mol}^{-1}$ & $\sigma / \mathrm{mS} \mathrm{cm}^{-1}$ \\
\hline \multirow{3}{*}{293.15} & 0.0501 & 0.3181 & 0.3158 & 8.31 \\
& 0.0756 & 0.3083 & 0.3091 & 9.87 \\
& 0.1279 & 0.2881 & 0.2872 & 8.03 \\
& 0.1628 & 0.2757 & 0.2753 & 5.98 \\
\hline \multirow{3}{*}{313.15} & 0.0501 & 0.3181 & 0.3158 & 11.35 \\
& 0.0756 & 0.3083 & 0.3091 & 14.12 \\
& 0.1279 & 0.2881 & 0.2872 & 12.69 \\
& 0.1628 & 0.2757 & 0.2753 & 10.31 \\
\hline \multirow{3}{*}{333.15} & 0.0501 & 0.3181 & 0.3158 & 14.58 \\
& 0.0756 & 0.3083 & 0.3091 & 18.57 \\
& 0.1279 & 0.2881 & 0.2872 & 17.79 \\
& 0.1628 & 0.2757 & 0.2753 & 15.19 \\
\hline \hline
\end{tabular}

Table 5: Parameters of the correlation function Eq. (1) for the electrical conductivity in the system LiFSI-DMC-EC-PC.

\begin{tabular}{ccccc}
\hline \hline system & $c_{k, j, 01}$ & $c_{k, j, 02}$ & $c_{k, j, 1}$ & $c_{k, j, 2}$ \\
\hline LiFSI-DMC-EC & 15686.23 & 366.21 & -15242.62 & 6440.98 \\
LiFSI-DMC-PC & 19597.17 & 395.53 & -33141.62 & 13708.82 \\
LiFSI-EC-PC & 1.87 & - & - & - \\
\hline \hline
\end{tabular}




\section{Multi-objective optimization}

\subsection{Method}

In the following, it is shown how multi-objective optimization can be used for designing the electrolyte solution for LiB. We only discuss an example here to illustrate the method. In practical applications other objectives, constraints, and design parameters could be relevant. In the present example, the decision space contains two conflicting objectives corresponding to the performance and costs of the electrolyte solution: the electrical conductivity $\sigma$, which shall be maximal, and the LiFSI concentration, which shall be minimal (see Tab. 7). The design space comprises the composition of the solvent and the concentration of LiFSI as free design parameters, see Tab. 6. Here, the salt is always LiFSI and the mole fraction of LiFSI is below $0.2 \mathrm{~mol} \mathrm{~mol}^{-1}$. The solvent constituents are DMC, EC, and PC, pure solvents and all mixtures are admissible. Further, the temperature $T$ is set as constant in the design space. Different temperatures are chosen from the range between 273 and $333 \mathrm{~K}$. The optimization is carried out individually for each temperature, and the results are then combined in the decision process. A constraint is introduced that requires that no solid precipiation occurs. For applying, this constraint the solid-liquid equilibrium in the salt-free solvent system DMC-EC-PC is modeled and used. As adding salt leads to a freezing point depression, this corresponds to a conservative estimate. A detailed description of the modeling is given in Appendix B.

The multi-objective optimization problem was solved with the $\epsilon$-constraint 
method. The calculations were carried out in Matlab 2016 using the solver fmincon. The $\epsilon$-constraint method is described in detail in the work of Finlayson et al. [41]. In this method, the multi-objective optimization problem is reformulated to obtain a series of single-objective optimization problems. For the present problem, it can be written as:

$$
\begin{aligned}
\max \sigma\left(x_{\mathrm{LiFSI}}, \underline{x}_{\mathrm{solv}}, T\right) \quad \text { s.t. } & x_{\mathrm{LiFSI}, j} \leq \epsilon_{j} \\
& T \geq T_{j}^{f}\left(\underline{x}_{\text {solv }}\right)
\end{aligned}
$$

where $j \in \mathbb{N}_{+} \cdot \underline{x}_{\text {solv }}$ is the vector of the solvent concentrations $\left(x_{\mathrm{DMC}}, x_{\mathrm{PC}}\right)$. $T_{\underline{x}_{\text {solv }, j}}^{f}$ is the normal melting temperature at $\underline{x}_{\text {solv }} \cdot \epsilon_{j}$ is the constraint of the second objective: $\min x_{\text {LiFSI }}$ (cf. Tab. 7). For each single-objective optimization problem a solution $\sigma\left(x_{\mathrm{LiFSI}}, \underline{x}_{\mathrm{solv}}, T\right)$ is obtained. Each of these solutions is a point of the Pareto set and for each of these points also the composition of the solvent is known.

In the decision process the best compromise between the conflicting objectives has to be chosen. In the present case, a solvent composition and a salt concentration have to be selected. A strategy to do this based on the information from the Pareto sets for the individual temperatures is described below. Also that strategy is not unique, it is just an example. More details are given in Appendix A. 


\subsection{Results}

Fig. 4 depicts the decision space of the multi-objective optimization problem described above. Each curve in Fig. 4 represents a Pareto set for a different temperature. Symbols on the Pareto sets represent the maxima (squares), and the chosen best compromises (diamonds). They were obtained as described in more detail in the Appendix A following the idea that a certain decline in the electrical conductivity is acceptable if the amount of LiFSI which is needed can be reduced substantially. For each of these best compromises not only the salt concentration is different but also the solvent composition. Based on the information of the Pareto sets a final optimization was performed (see Appendix A) to obtain a single electrolyte solution $\left(x_{\mathrm{LiFSI}}, \underline{x}_{\text {solv }}\right)$ that minimizes the deviations between the chosen best compromises and the final solution over the complete temperature range of interest; here, 273 to $333 \mathrm{~K}$. The circles represent the electrolyte solution obtained by the final optimization. For this solution, both salt concentration and solvent composition are fixed. Numerical values of the solutions, which are represented by symbols in Fig. 4, are reported in Tab. 8. Numerical values of each of the solutions of the Pareto sets in the studied temperature range are reported in Tab. S1 in the Supporting Information.

The trade-off between the two objectives can be seen in the shape of the Pareto sets: for an increase in the electrical conductivity an increase in the concentration of conductive salt (LiFSI) has to be accepted. There is a con- 
centration at which there is no further conflict: a further increase of the mole fraction of LiFSI leads to a decrease in the electrical conductivity and thus, this range of solutions is not Pareto-optimal. For increasing temperature, the maximum of the electrical conductivity increases strongly. In the studied temperature range from 273 to $333 \mathrm{~K}$ the electrical conductivity rises from 8.8 to $19.3 \mathrm{mS} \mathrm{cm}{ }^{-1}$. The mole fraction of LiFSI at the maxima of the electrical conductivity shifts from 0.07 to $0.10 \mathrm{~mol} \mathrm{~mol}^{-1}$ in the studied temperature range.

Tab. 8 shows that for temperatures between 283 and $333 \mathrm{~K}$ all maxima as well as all best compromises on the Pareto sets are located in the binary solvent mixture DMC-EC. Only for $273 \mathrm{~K}$ an addition of $\mathrm{PC}$ is required to decrease the melting temperature of the solution. Accordingly, also the solvent, which is finally chosen, contains PC. Further, as expected, an increase in the concentration of LiFSI has to be accepted, compared to the concentration of LiFSI of the best compromises of the individual Pareto-sets. The mean relative deviation in the electrical conductivity of the chosen best compromises for each isotherm and the final result is below $0.5 \%$.

Table 6: Design parameters of the multi-objective optimization.

\begin{tabular}{cc}
\hline \hline Free design parameter & Range \\
\hline$x_{\mathrm{LiFSI}}$ & {$\left[0.0 \mathrm{~mol} \mathrm{~mol}^{-1}, 0.2 \mathrm{~mol} \mathrm{~mol}^{-1}\right]$} \\
$x_{\mathrm{DMC}}$ & {$\left[0.0 \mathrm{~mol} \mathrm{~mol}^{-1}, 1.0 \mathrm{~mol} \mathrm{~mol}^{-1}\right]$} \\
$x_{\mathrm{PC}}$ & {$\left[0.0 \mathrm{~mol} \mathrm{~mol}^{-1}, 1.0 \mathrm{~mol} \mathrm{~mol}{ }^{-1}\right]$} \\
\hline \hline Set design parameter & Range \\
\hline$T$ & {$[273.15 \mathrm{~K}, 333.15 \mathrm{~K}]$} \\
\hline \hline
\end{tabular}




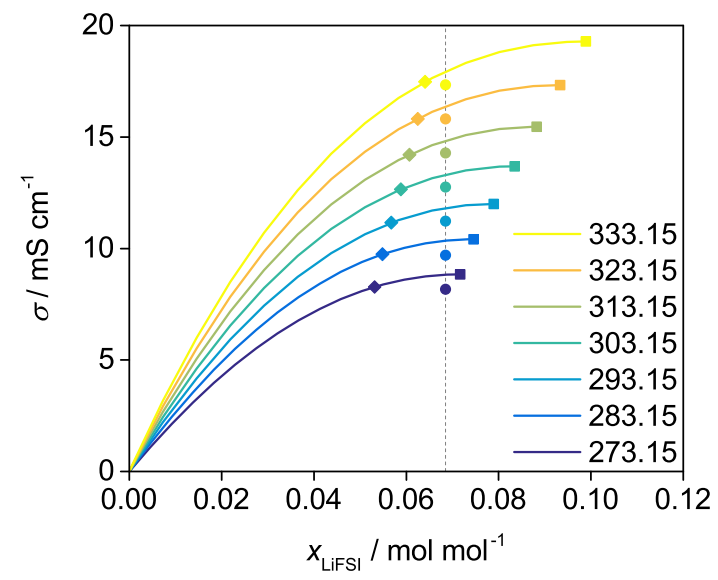

Figure 4: Decision space of the two conflicting objectives: maximizing the electrical conductivity and minimizing the mole fraction of LiFSI for different temperatures. The solid lines represent the Pareto set for the given temperature. Symbols on the Pareto sets represent the maxima (squares) and the chosen best compromises (diamonds). The circles represent the final solution and are underlaid with a dash-line to indicate the constant mole fraction of LiFSI.

Table 7: Objectives of the multi-objective optimization.

\begin{tabular}{ccc}
\hline \hline Objective & Symbol & Goal \\
\hline Electrical conductivity & $\sigma$ & Maximize \\
Mole fraction of LiFSI & $x_{\text {LiFSI }}$ & Minimize \\
\hline \hline
\end{tabular}

\section{Conclusions}

In the present work, the electrical conductivity of solutions of lithium bis(fluorosulfonyl)imide (LiFSI) in binary and ternary solvent mixtures of dimethyl carbonate (DMC), ethylene carbonate (EC) and propylene carbonate (PC) were 
Table 8: Overview of the numerical values of the composition and electrical conductivity for the maxima and the chosen best compromises on the Pareto-sets, and the final solution.

\begin{tabular}{|c|c|c|c|c|c|}
\hline $\begin{array}{l}T \\
\mathrm{~K}\end{array}$ & $\begin{array}{c}x_{\text {LiFSI }} \\
\mathrm{mol} \mathrm{mol}^{-1}\end{array}$ & $\begin{array}{c}x_{\mathrm{DMC}} \\
\mathrm{mol} \mathrm{mol}^{-1}\end{array}$ & $\begin{array}{c}x_{\mathrm{PC}} \\
\mathrm{mol} \mathrm{mol}^{-1}\end{array}$ & $\begin{array}{c}\sigma \\
\mathrm{mS} \mathrm{cm}^{-1}\end{array}$ & $\begin{array}{l}c_{\mathrm{LiFSI}}{ }^{*} \\
\mathrm{~mol} \mathrm{l}^{-1}\end{array}$ \\
\hline \multicolumn{6}{|c|}{ Pareto maxima } \\
\hline 273.15 & 0.0717 & 0.5423 & 0.0220 & 8.84 & 0.99 \\
\hline 283.15 & 0.0745 & 0.4843 & 0.0000 & 10.41 & 1.04 \\
\hline 293.15 & 0.0790 & 0.4646 & 0.0000 & 12.00 & 1.10 \\
\hline 303.15 & 0.0835 & 0.4464 & 0.0000 & 13.68 & 1.15 \\
\hline 313.15 & 0.0883 & 0.4297 & 0.0000 & 15.46 & 1.21 \\
\hline 323.15 & 0.0933 & 0.4144 & 0.0000 & 17.33 & 1.27 \\
\hline 333.15 & 0.0989 & 0.4006 & 0.0000 & 19.29 & 1.33 \\
\hline \multicolumn{6}{|c|}{ Chosen best compromises } \\
\hline 273.15 & 0.0532 & 0.5221 & 0.0428 & 8.28 & 0.73 \\
\hline 283.15 & 0.0549 & 0.4710 & 0.0000 & 9.74 & 0.77 \\
\hline 293.15 & 0.0568 & 0.4413 & 0.0000 & 11.16 & 0.79 \\
\hline 303.15 & 0.0588 & 0.4211 & 0.0000 & 12.65 & 0.81 \\
\hline 313.15 & 0.0607 & 0.4023 & 0.0000 & 14.21 & 0.83 \\
\hline 323.15 & 0.0625 & 0.3848 & 0.0000 & 15.82 & 0.85 \\
\hline 333.15 & 0.0641 & 0.3685 & 0.0000 & 17.47 & 0.87 \\
\hline \multicolumn{6}{|c|}{ Final solution } \\
\hline 273.15 & & & & 8.18 & 0.96 \\
\hline 283.15 & & & & 9.70 & 0.95 \\
\hline 293.15 & & & & 11.23 & 0.94 \\
\hline 303.15 & 0.0685 & 0.3637 & 0.1488 & 12.76 & 0.93 \\
\hline 313.15 & & & & 14.29 & 0.92 \\
\hline 323.15 & & & & 15.82 & 0.91 \\
\hline 333.15 & & & & 17.34 & 0.90 \\
\hline
\end{tabular}

${ }^{*}$ Molarities of LiFSI in mixtures of DMC, EC, and PC calculated with Eq. (12). For further details see Appendix 4.2. 
studied experimentally at temperatures between 293 and $333 \mathrm{~K}$, at ambient pressure and concentrations of LiFSI up to $0.2 \mathrm{~mol} \mathrm{~mol}^{-1}$. A correlation of the experimental data is provided. A multi-objective optimization strategy is presented to find electrolyte solutions of an optimal composition for the conflicting objectives: maximizing electrical conductivity and minimizing conductive salt (LiFSI) content. These objectives can be seen as representatives of the aims: maximization of performance and reduction costs of the LiB, respectively. The solubility limits of the ternary solvent system DMC-EC-PC were included in the optimization as constraints. The multi-objective optimization strategy applied here can easily be extended to include more objectives and constraints, and is thus a powerful tool for the rational optimization of battery electrolyte solutions.

\section{References}

[1] B. Scrosati, J. Garche, Lithium batteries: Status, prospects and future, Journal of Power Sources 195 (9) (2010) 2419-2430. doi:10.1016/j.jpowsour.2009.11.048.

[2] A. Thielmann, A. Sauer, M. Wietschel, Gesamt-Roadmap Lithium-IonenBatterien 2030, Tech. rep., Fraunhofer-Institut für System- und Innovationsforschung ISI, Karlsruhe (2015).

[3] T. Stocker, D. Qin, G.-K. Plattner, M. Tignor, S. Allen, J. Boschung, A. Nauels, Y. Xia, V. Bex, P. Midgley, IPCC, 2013: Climate Change 2013: The Physical Science Basis. Contribution of Working Group I to the Fifth 
Assessment Report of the Intergovernmental Panel on Climate Change, Tech. rep., Cambridge University Press, Cambridge, United Kingdom and New York, NY, USA (2013).

[4] J.-M. Tarascon, M. Armand, Issues and challenges facing rechargeable lithium batteries, in: Materials For Sustainable Energy: A Collection of Peer-Reviewed Research and Review Articles from Nature Publishing Group, World Scientific, 2011, pp. 171-179.

[5] Y. Nishi, Lithium ion secondary batteries; past 10 years and the future, Journal of Power Sources 100 (1) (2001) 101-106.

[6] H. Ota, K. Shima, M. Ue, J.-I. Yamaki, Effect of vinylene carbonate as additive to electrolyte for lithium metal anode, Electrochimica Acta 49 (4) (2004) 565-572. doi:10.1016/j.electacta.2003.09.010.

[7] S. S. Zhang, A review on electrolyte additives for lithium-ion batteries, Journal of Power Sources 162 (2) (2006) 1379-1394. doi:10.1016/j.jpowsour.2006.07.074.

[8] G. E. Blomgren, Electrolytes for advanced batteries, Journal of Power Sources 81 (1999) 112-118.

[9] G. E. Blomgren, Liquid electrolytes for lithium and lithiumion batteries, Journal of Power Sources 119-121 (2003) 326-329. doi:10.1016/S0378-7753(03)00147-2.

[10] C. L. Berhaut, P. Porion, L. Timperman, G. Schmidt, D. Lemor- 
dant, M. Anouti, Litdi as electrolyte salt for li-ion batteries: transport properties in ec/dmc, Electrochimica Acta 180 (2015) 778 - 787. doi:https://doi.org/10.1016/j.electacta.2015.08.165.

[11] G. E. Blomgren, The Development and Future of Lithium Ion Batteries, Journal of The Electrochemical Society 164 (1) (2017) A5019-A5025. doi:10.1149/2.0251701jes.

[12] J. Neuhaus, E. von Harbou, H. Hasse, Physico-chemical properties of solutions of lithium bis(fluorosulfonyl)imide (LiFSI) in dimethyl carbonate, ethylene carbonate, and propylene carbonate, Journal of Power Sources 394 (2018) 148-159. doi:10.1016/j.jpowsour.2018.05.038.

[13] H.-B. Han, S.-S. Zhou, D.-J. Zhang, S.-W. Feng, L.-F. Li, K. Liu, W.F. Feng, J. Nie, H. Li, X.-J. Huang, M. Armand, Z.-B. Zhou, Lithium bis(fluorosulfonyl)imide (LiFSI) as conducting salt for nonaqueous liquid electrolytes for lithium-ion batteries: Physicochemical and electrochemical properties, Journal of Power Sources 196 (7) (2011) 3623-3632. doi:10.1016/j.jpowsour.2010.12.040.

[14] S.-D. Han, O. Borodin, D. M. Seo, Z.-B. Zhou, W. A. Henderson, Electrolyte solvation and ionic association V. Acetonitrile-lithium bis (fluorosulfonyl) imide (LiFSI) mixtures, Journal of The Electrochemical Society 161 (14) (2014) A2042-A2053.

[15] S. Lux, I. Lucas, E. Pollak, S. Passerini, M. Winter, R. Kostecki, The mechanism of $\mathrm{HF}$ formation in $\mathrm{LiPF}_{6}$ based organic carbon- 
ate electrolytes, Electrochemistry Communications 14 (1) (2012) 47-50. doi:10.1016/j.elecom.2011.10.026.

[16] G. G. Eshetu, S. Grugeon, G. Gachot, D. Mathiron, M. Armand, S. Laruelle, LiFSI vs. $\mathrm{LiPF}_{6}$ electrolytes in contact with lithiated graphite: Comparing thermal stabilities and identification of specific SEI-reinforcing additives, Electrochimica Acta 102 (2013) 133-141. doi:10.1016/j.electacta.2013.03.171.

[17] C. Forestier, S. Grugeon, C. Davoisne, A. Lecocq, G. Marlair, M. Armand, L. Sannier, S. Laruelle, Graphite electrode thermal behavior and solid electrolyte interphase investigations: Role of state-of-the-art binders, carbonate additives and lithium bis(fluorosulfonyl)imide salt, Journal of Power Sources 330 (2016) 186-194. doi:10.1016/j.jpowsour.2016.09.005.

[18] J. Wang, Y. Yamada, K. Sodeyama, C. H. Chiang, Y. Tateyama, A. Yamada, Superconcentrated electrolytes for a high-voltage lithium-ion battery, Nature Communications 7 (2016) 12032. doi :10.1038/ncomms12032.

[19] K. Xu, Nonaqueous Liquid Electrolytes for Lithium-Based Rechargeable Batteries, Chemical Reviews $104 \quad(10) \quad$ (2004) 4303-4418. doi : 10.1021/cr030203g.

[20] T. Takekawa, K. Kamiguchi, H. Imai, M. Hatano, Physicochemical and Electrochemical Properties of the Organic Solvent Electrolyte with Lithium Bis(fluorosulfonyl)Imide (LiFSI) As Lithium-Ion Conducting Salt 
for Lithium-Ion Batteries, ECS Transactions 64 (24) (2015) 11-16. doi:10.1149/06424.0011ecst.

[21] S. Uchida, M. Ishikawa, Lithium bis(fluorosulfonyl)imide based low ethylene carbonate content electrolyte with unusual solvation state, Journal of Power Sources $359 \quad(2017) \quad 480-486$. doi:10.1016/j.jpowsour.2017.05.090.

[22] L. Li, S. Zhou, H. Han, H. Li, J. Nie, M. Armand, Z. Zhou, X. Huang, Transport and Electrochemical Properties and Spectral Features of Non-Aqueous Electrolytes Containing LiFSI in Linear Carbonate Solvents, Journal of The Electrochemical Society 158 (2) (2011) A74-A82. doi:10.1149/1.3514705.

[23] M. Bortz, J. Burger, N. Asprion, S. Blagov, R. Böttcher, U. Nowak, A. Scheithauer, R. Welke, K.-H. Küfer, H. Hasse, Multi-criteria optimization in chemical process design and decision support by navigation on Pareto sets, Computers \& Chemical Engineering 60 (2014) 354-363. doi:10.1016/j.compchemeng.2013.09.015.

[24] J. Burger, N. Asprion, S. Blagov, R. Böttcher, U. Nowak, M. Bortz, R. Welke, K.-H. Küfer, H. Hasse, Multi-Objective Optimization and Decision Support in Process Engineering - Implementation and Application, Chemie Ingenieur Technik $86 \quad$ (7) (2014) 1065-1072. doi:10.1002/cite. 201400008 .

[25] N. Asprion, S. Blagov, O. Ryll, R. Welke, A. Winterfeld, A. Dittel, 
M. Bortz, K.-H. Küfer, J. Burger, A. Scheithauer, H. Hasse, Decission Support for Process Development in the Chemical Industry, Chemical Engineering Transaction 24 (2011) 301-306. doi:10.3303/CET1124051.

[26] A. Hugo, C. Ciumei, A. Buxton, E. N. Pistikopoulos, Environmental impact minimization through material substitution: a multi-objective optimization approach, Green Chemistry 6 (8) (2004) 407. doi:10.1039/b401868k.

[27] H. Renon, J. M. Prausnitz, Local compositions in thermodynamic excess functions for liquid mixtures, AIChE Journal 14 (1) (1968) 135-144. doi:10.1002/aic.690140124.

[28] M. S. Ding, Liquid-Solid Phase Equilibria and Thermodynamic Modeling for Binary Organic Carbonates, Journal of Chemical \& Engineering Data 49 (2) (2004) 276-282. doi:10.1021/je034134e.

[29] O. Borodin, G. D. Smith, Quantum Chemistry and Molecular Dynamics Simulation Study of Dimethyl Carbonate: Ethylene Carbonate Electrolytes Doped with $\mathrm{LiPF}_{6}$, The Journal of Physical Chemistry B 113 (6) (2009) 1763-1776. doi:10.1021/jp809614h.

[30] R. Francesconi, F. Comelli, Vapor-Liquid Equilibria, Excess Molar Enthalpies, and Excess Molar Volumes of Dimethyl Carbonate $+1,2-$ Epoxybutane at 288.15, 298.15, or 313.15 K, Journal of Chemical \& Engineering Data 41 (4) (1996) 736-740. doi:10.1021/je950298m.

[31] P. T. Thompson, B. Fisher, R. H. Wood, Viscosities of solutions of elec- 
trolytes and non-electrolytes in ethylene carbonate at $40{ }^{\circ} \mathrm{C}$, Journal of Solution Chemistry 11 (1) (1982) 1-15. doi:10.1007/BF00664330.

[32] J. Barthel, H.-J. Gores, P. Carlier, F. Feuerlein, M. Utz, The Temperature Dependence of the Properties of Electrolyte Solutions. V. Determination of the Glass Transition Temperature and Comparison of the Temperature Coefficients of Electrolyte Conductance and Solvent Viscosity of Propylene Carbonate Solutions, Berichte der Bunsengesellschaft für physikalische Chemie 87 (5) (1983) 436-443. doi:10.1002/bbpc.19830870516.

[33] A. Rodriguez, A. B. Pereiro, J. Canosa, J. Tojo, Dynamic viscosities of the ternary liquid mixtures (dimethyl carbonate + methanol + ethanol) and (dimethyl carbonate + methanol + hexane) at several temperatures, The Journal of Chemical Thermodynamics 38 (5) (2006) 505-519. doi:10.1016/j.jct.2005.07.008.

[34] S.-I. Tobishima, K. Hayashi, K.-I. Saito, J.-I. Yamaki, Ethylene carbonate-based ternary mixed solvent electrolytes for rechargeable lithium batteries, Electrochimica Acta 40 (5) (1995) 537-544. doi : 10.1016/0013-4686(95) 00004-X.

[35] K. Hayamizu, Y. Aihara, S. Arai, C. G. Martinez, Pulse-Gradient SpinEcho ${ }^{1} \mathrm{H},{ }^{7} \mathrm{Li}$, and ${ }^{19} \mathrm{~F}$ NMR Diffusion and Ionic Conductivity Measurements of 14 Organic Electrolytes Containing $\mathrm{LiN}\left(\mathrm{SO}_{2} \mathrm{CF}_{3}\right)_{2}$, The Journal of Physical Chemistry B 103 (3) (1999) 519-524. doi:10.1021/jp9825664.

[36] N. Nanbu, M. Takehara, S. Watanabe, M. Ue, Y. Sasaki, Polar Effect 
of Successive Fluorination of Dimethyl Carbonate on Physical Properties, Bulletin of the Chemical Society of Japan 80 (7) (2007) 1302-1306.

[37] R. Payne, I. E. Theodorou, Dielectric properties and relaxation in ethylene carbonate and propylene carbonate, The Journal of Physical Chemistry 76 (20) (1972) 2892-2900.

[38] J. C. Wadsworth, The Statistical Description of Precision Conductivity Data for Aqueous Sodium Chloride, Journal of Solution Chemistry 41 (4) (2012) 715-729. doi:10.1007/s10953-012-9823-6.

[39] O. Borodin, M. Olguin, P. Ganesh, P. R. C. Kent, J. L. Allen, W. A. Henderson, Competitive lithium solvation of linear and cyclic carbonates from quantum chemistry, Phys. Chem. Chem. Phys. 18 (1) (2016) 164-175. doi:10.1039/C5CP05121E.

[40] T. Li, P. B. Balbuena, Theoretical Studies of Lithium Perchlorate in Ethylene Carbonate, Propylene Carbonate, and Their Mixtures, Journal of The Electrochemical Society 146 (10) (1999) 3613-3622. doi:S0013-4651(99)03-062-1.

[41] B. A. Finlayson, L. T. Biegler, I. E. Grossmann, K.-H. Küfer, M. Bortz, Mathematics in Chemical Engineering, in: Ullmann's Encyclopedia of Industrial Chemistry, Wiley-VCH Verlag GmbH \& Co. KGaA, 2000, pp. 1161, dOI: 10.1002/14356007.b01_01.pub3.

[42] J. M. Prausnitz, R. N. Lichtenthaler, E. G. de Azevedo, Molecular Ther- 
modynamics of Fluid-Phase Equilibria, third edition Edition, Prentice-Hall

Inc., Englewood Cliffs, New Jersey, 1999, bibtex: prausnitz. 


\section{Appendix A. Multi-objective optimization}

In the decision process, the best compromise between the conflicting objectives has to be chosen. Here, we defined a derivative based weight:

$$
\begin{aligned}
\sigma^{*} & =\sigma\left(x_{\mathrm{LiFSI}}^{*}, \underline{x}_{\text {solv }}, T\right) \\
\left.\frac{\partial \sigma}{\partial x_{\mathrm{LiFSI}}}\right|_{x_{\mathrm{LFSI}}^{*}} & =\left.\frac{1}{4} \frac{\partial \sigma}{\partial x_{\mathrm{LiFSI}}}\right|_{x_{\mathrm{LiFSI}} \rightarrow 0}
\end{aligned}
$$

where we have chosen that an addition of salt is reasonable until the response in the electrical conductivity reaches $25 \%$ of its maximum response.

With the information of the identified best compromises, a final optimization is formulated as follows:

$$
\underline{x}=\underset{\underline{x} \in[0,1]}{\arg \min } \sum_{i}\left|\sigma\left(x_{\mathrm{LiFSI}}, \underline{x}_{\mathrm{solv}}, T_{i}\right)-\sigma\left(x_{\mathrm{LiFSI}, i}^{*}, \underline{x}_{\mathrm{solv}, i}, T_{i}\right)\right|
$$

where $i=(273,283, \ldots, 333) \mathrm{K}$. The solution of this final optimization leads to a single electrolyte solution $\left(\underline{x}=\left(x_{\text {LiFSI }}, \underline{x}_{\text {solv }}\right)\right)$ that minimizes the deterioration in the electrical conductivity over the complete temperature range of interest; here, 273 to $333 \mathrm{~K}$. The obtained electrolyte solution remains liquid over the temperature range, which is assured by the constraint introduced (see Eq. (8)). Results of this optimization strategy are shown in Section 3.2. 


\section{Appendix B. Solid-liquid equilibrium}

\subsection{Correlation}

For the description of the solid-liquid equilibria in the binary solvent systems DMC-EC, DCM-PC, and EC-PC, Eq. (11) was fitted to experimental data from Ding et al. [28]. It is assumed that the solid phases which are formed contain only a pure solvent. Then, Eq. (11) describes implicitly the dependence of the liquidus line (solubility limit) on the temperature and the composition of the mixture:

$$
\frac{\Delta h_{i}^{f}}{R T_{i}^{f}}\left(\frac{T_{i}^{f}}{T}-1\right)+\ln \left(x_{i} \gamma_{i}\right)=0
$$

where $R$ is the universal gas constant. $T_{i}^{f}$ and $\Delta h_{i}^{f}$ are the normal melting temperature and the enthalpy of fusion of the pure component $i$ (cf. Tab. 2). $x_{i}$ and $\gamma_{i}$ are the mole fraction and the activity coefficient of component $i$ in the liquid phase. The dependence of the activity coefficient on the temperature and composition is described with the NRTL model [27, 42].

The solubility limit (liquidus surface) in the ternary system DMC-EC-PC is obtained by solving Eq. (11) for each component $i$. For a given composition $\underline{x}$ the solution yield three different temperatures $T_{i, \underline{x}}^{f}$ with $i=$ (DMC, EC, PC) of which the largest one is that of the solubility limit and the corresponding $i$ indicates which solvent precipitates for the chosen $\underline{x}$.

The adjustable parameters in the correlations presented above were determined from a fit to the corresponding experimental activity coefficients $\gamma_{i}^{\exp }$. 
The sum of the squared relative errors between the experimental data and the correlation $e_{j}=\left(\gamma_{j}^{\text {corr }}-\gamma_{i}^{\exp }\right) / \gamma_{i}^{\exp }$ was employed as objective function. The optimization was carried out in Matlab 2016b using the solver lsqnonlin.

\subsection{Results}

The experimental data of Ding et al. [28] and the corresponding NRTLmodel fits from this work are shown in Fig. B1. The parameters of the NRTLmodel are reported in Tab. B1. The correlations describe the experimental data well in all of the three systems. The mean absolute deviation between correlation and the experimental data for (DMC-EC, DMC-PC, EC-PC) are (0.5, $0.3,2.1) \mathrm{K}$. The calculated values are well within the experimental uncertainty, which is to be expected for differential scanning calorimetry (DSC) that Ding et al. employed for their measurements.

By means of the binary interaction parameters of the NRTL-model (cf. Tab. B1) obtained by experimental data of the solid-liquid equilibria in the binary systems, the activity of the single solvents in the ternary system DMCEC-PC can be predicted. Thus, the liquidus area in the ternary system DMCEC-PC can be calculated. The resulting liquidus-surface, which was used for defining the inequality constraint in the multi-objective optimization, is depicted in Fig. S1. 

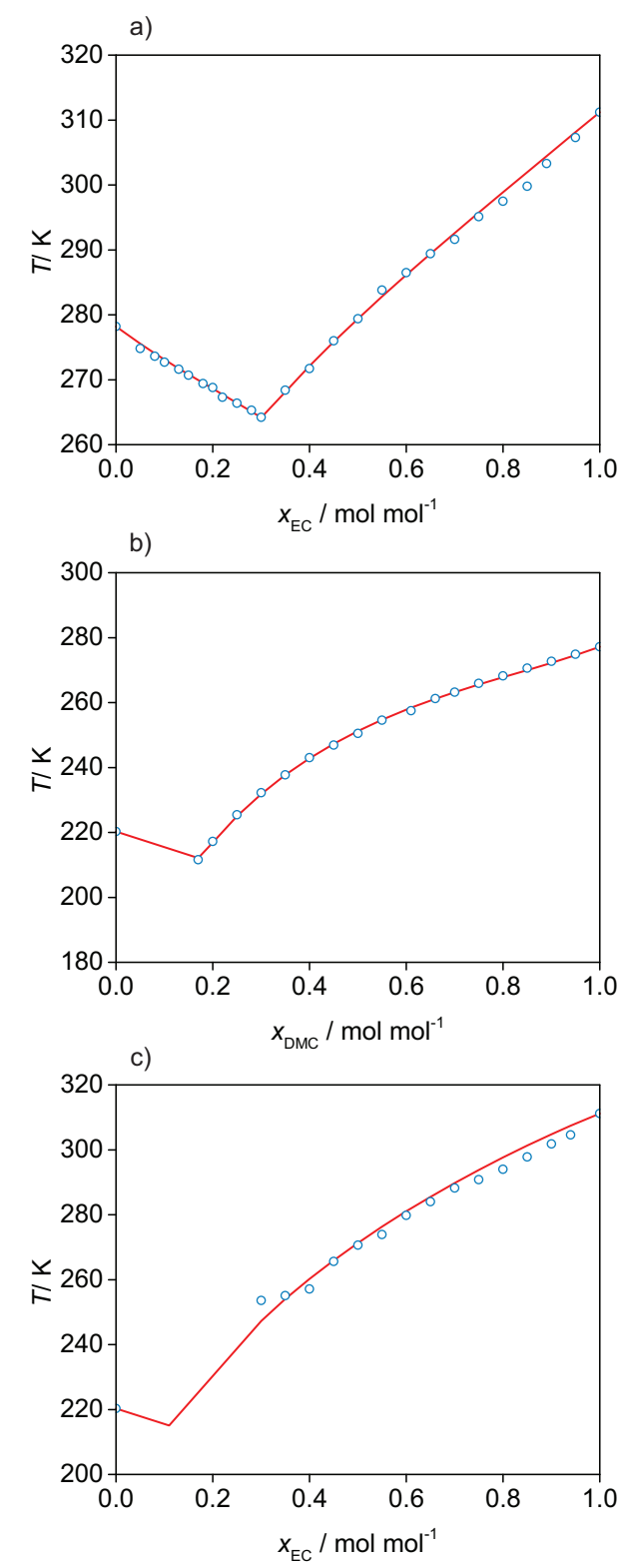

Figure B1: Solid-liquid equilibrium in the binary solvent systems a) DMC-EC, b) DMC-PC, and c) EC-PC. Symbols: Experimental data from [28]. Solid Lines: NRTLfits of Eq. (11) with parameters from Tab. B1. 
Table B1: Parameters of the NRTL model [27] of the solid-liquid equilibria in the binary carbonate systems DMC-EC, DMC-PC, and EC-PC . Based on the experimental data taken from [28]. $\tau_{i j}$ defined as follows: $\tau_{i j}=\frac{b_{i j}}{\frac{T}{\mathrm{~K}}} \cdot \alpha$ is 0.3 for all systems.

\begin{tabular}{cccc}
\hline \hline Component $i$ & DMC & DMC & EC \\
Component $j$ & EC & PC & PC \\
\hline$b_{i j} / \mathrm{K}$ & 685.73 & 929.09 & 213.31 \\
$b_{j i} / \mathrm{K}$ & -207.31 & -408.36 & -286.81 \\
\hline \hline
\end{tabular}




\section{Appendix C. Molarity of LiFSI in mixtures of DMC, EC, and PC}

For the calculation of the molarity of LiFSI in mixtures of DMC, EC, and $\mathrm{PC}$ a regular mixing rule is used, see Eq. (12). In that mixing rule, it is assumed that no mixed-solvent effects are present, i.e. excess volumina. The molarity of LiFSI in the mixed solvent is calculated from the molarities of LiFSI in the pure solvents DMC, EC, and PC for which data on the densities is available from our previous work [12]. Then, Eq. (12) describes implicitly the dependence of the molarity of mixture on the temperature and the composition of the mixture:

$$
\left(\frac{c_{\mathrm{LiFSI}}}{\mathrm{mol} \mathrm{l}^{-1}}\right)=\sum_{i} \tilde{x}_{i} c_{\mathrm{LiFSI}, i} \quad \text { with } \quad i=(\mathrm{DMC}, \mathrm{EC}, \mathrm{PC})
$$

where $\tilde{x}_{i}$ is the normalized mole fraction of solvent $i$ that is defined in Eq. (13).

$$
\tilde{x}_{i}=\frac{n_{i}}{n_{\mathrm{DMC}}+n_{\mathrm{EC}}+n_{\mathrm{PC}}}
$$

The $c_{\mathrm{LiFSI}, i}$ are the molarities of LiFSI in the pure solvents $i$ that can be calculated from Eq. (14).

$$
\left(\frac{c_{\mathrm{LiFSI}, i}}{\mathrm{~mol} \mathrm{l}^{-1}}\right)=\frac{x_{\mathrm{LiFSI}, i} \rho_{i}}{M_{i} \times 1000}
$$

where $\rho_{i}$ is the specific density taken from [12], $M_{i}$ is the molar mass of mixture and $x_{\mathrm{LiFSI}, i}$ is the mole fraction of LiFSI in the pure solvent $i$. 
Supporting Information on: Electrical conductivity of solutions of LiFSI in mixed organic solvents and multi-objective solvent optimization for lithium-ion batteries 


\section{Multi-objective Optimization: Design Space and Decision Process}

Fig. S1 shows the design space of the two conflicting objectives: maximizing electrical conductivity and minimizing mole fraction of LiFSI at temperatures between 273 and $333 \mathrm{~K}$. The symbols represent the images of the single solutions of the Pareto sets with colors correspond to the temperature $T$ (see Fig. 4 in the main document). The red-marked symbols indicate the maxima of the electrical conductivity for each isothermal Pareto-set. The surface represents the predicted solid-liquid equilibrium in the ternary solvent system DMC-EC-PC; for further information see Appendix A in the main document.

Fig. S2 shows (panel a)) the design space of the two conflicting objectives: maximizing electrical conductivity and minimizing mole fraction of LiFSI, and (panel b)) mean relative deviation between the electrolyte solutions obtained by the final optimization problem and the electrolyte solutions of the Pareto sets for the individual temperatures. The symbols represent the images of the electrolyte solutions obtained by the final optimization problem. The final solution (overall minimal average deviation) is indicated by the red circle. Further solutions for lower concentrations of LiFSI are indicted by crosses. The lines in panel a) are the isotherms of the predicted solid-liquid equilibrium in the ternary solvent system DMC-EC-PC. For further information see Section 3.1 and Appendix A in the main document. 


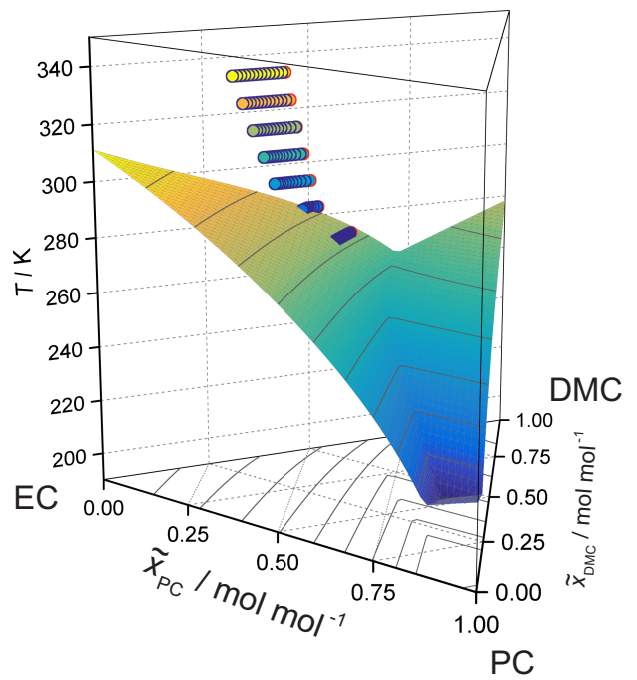

Figure S1: Design space of the two conflicting objectives: maximizing electrical conductivity and minimizing mole fraction of LiFSI at temperatures between 273 and 333 K. Symbols: images of the single solutions of the Pareto sets; colors correspond to the temperature $T$ (see Fig. 4); red-marked symbols indicate the maxima of the electrical conductivity for each isothermal Pareto-set. Surface: predicted solid-liquid equilibrium in the ternary solvent system DMC-EC-PC, cf. Appendix A in the main document. 


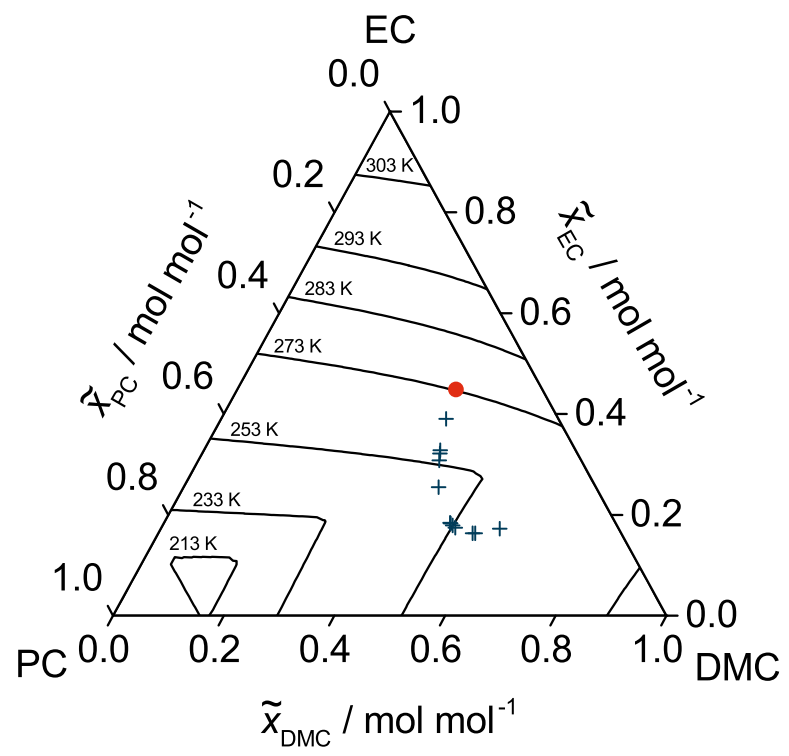

(a)

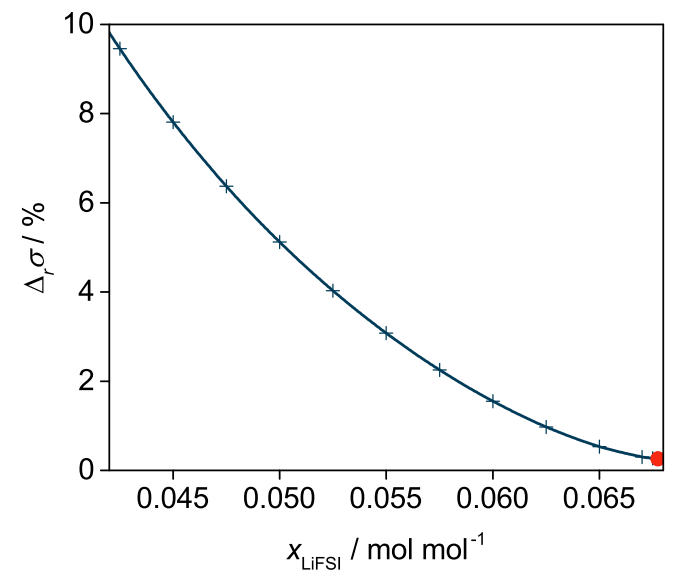

(b)

Figure S2: a) Design space of the two conflicting objectives: maximizing electrical conductivity and minimizing mole fraction of LiFSI; b) mean relative deviation between the electrolyte solutions obtained by the final optimization problem and the electrolyte solutions of the Pareto sets for the individual temperatures. Symbols represent the images of the electrolyte solutions obtained by the final optimization problem; the final solution ((overall minimal average deviation), red circle) and further solutions for lower concentrations of LiFSI (crosses). Lines: Isotherms of predicted solid-liquid equilibrium in the ternary solvent system 1 MC-EC-PC. For further information see Section 3.1 and Appendix A in the main document. 


\section{Multi-objective Optimization: Numerical Values}

Tab. S1 shows the numerical values of the solutions on the Pareto sets (best compromises) at temperatures between 273 and $333 \mathrm{~K}$, obtained by the procedure described in Section 3.1 in the main document.

Table S1: Numerical values of the solutions on the Pareto sets at temperatures between 273 and $333 \mathrm{~K}$ obtained by the procedure described in Section 3.1 in the main document.

\begin{tabular}{cccc}
\hline \hline & \multicolumn{2}{c}{$T=273.15 \mathrm{~K}$} \\
$x_{\text {LiFSI }} / \mathrm{mol} \mathrm{mol}^{-1}$ & $x_{\mathrm{DMC}} / \mathrm{mol} \mathrm{mol}^{-1}$ & $x_{\mathrm{PC}} / \mathrm{mol} \mathrm{mol}^{-1}$ & $\sigma / \mathrm{mS} \mathrm{cm}^{-1}$ \\
\hline 0.0717 & 0.5423 & 0.0220 & 8.84 \\
0.0688 & 0.5380 & 0.0260 & 8.82 \\
0.0642 & 0.5319 & 0.0318 & 8.75 \\
0.0596 & 0.5266 & 0.0372 & 8.60 \\
0.0550 & 0.5219 & 0.0422 & 8.38 \\
0.0504 & 0.5176 & 0.0469 & 8.09 \\
0.0458 & 0.5138 & 0.0514 & 7.73 \\
0.0413 & 0.5102 & 0.0557 & 7.29 \\
0.0367 & 0.5070 & 0.0598 & 6.78 \\
0.0321 & 0.5039 & 0.0639 & 6.19 \\
0.0275 & 0.5010 & 0.0678 & 5.52 \\
0.0229 & 0.4983 & 0.0716 & 4.79 \\
0.0183 & 0.4957 & 0.0754 & 3.97 \\
0.0138 & 0.4932 & 0.0791 & 3.09 \\
0.0092 & 0.4907 & 0.0827 & 2.13 \\
0.0046 & 0.4882 & 0.0865 & 1.10 \\
0.0000 & 0.0000 & 0.4776 & 0.00 \\
\hline & & & \\
\hline & & & \\
$x_{\text {LiFSI }} / \mathrm{mol} \mathrm{mol}^{-1}$ & $x_{\mathrm{DMC}} / \mathrm{mol} \mathrm{mol}{ }^{-1}$ & $x_{\mathrm{PC}} / \mathrm{mol} \mathrm{mol}^{-1}$ & $\sigma / \mathrm{mS} \mathrm{cm}{ }^{-1}$ \\
\hline 0.0745 & 0.4843 & 0.0000 & 10.41 \\
& & & \\
\hline
\end{tabular}




\begin{tabular}{|c|c|c|c|}
\hline 0.0733 & 0.4826 & 0.0000 & 10.41 \\
\hline 0.0688 & 0.4765 & 0.0000 & 10.36 \\
\hline 0.0642 & 0.4714 & 0.0000 & 10.23 \\
\hline 0.0596 & 0.4686 & 0.0000 & 10.03 \\
\hline 0.0550 & 0.4709 & 0.0000 & 9.75 \\
\hline 0.0504 & 0.4732 & 0.0000 & 9.39 \\
\hline 0.0458 & 0.4755 & 0.0000 & 8.95 \\
\hline 0.0413 & 0.4778 & 0.0000 & 8.42 \\
\hline 0.0367 & 0.4800 & 0.0000 & 7.82 \\
\hline 0.0321 & 0.4823 & 0.0000 & 7.13 \\
\hline 0.0275 & 0.4814 & 0.0020 & 6.35 \\
\hline 0.0229 & 0.4787 & 0.0051 & 5.50 \\
\hline 0.0183 & 0.4761 & 0.0081 & 4.56 \\
\hline 0.0138 & 0.4736 & 0.0112 & 3.54 \\
\hline 0.0092 & 0.4710 & 0.0142 & 2.44 \\
\hline 0.0046 & 0.4683 & 0.0174 & 1.26 \\
\hline 0.0000 & 0.0000 & 0.3732 & 0.01 \\
\hline \multicolumn{4}{|c|}{$T=293.15 \mathrm{~K}$} \\
\hline$x_{\mathrm{LiFSI}} / \mathrm{mol} \mathrm{mol}^{-1}$ & $x_{\mathrm{DMC}} / \mathrm{mol} \mathrm{mol}^{-1}$ & $x_{\mathrm{PC}} / \mathrm{mol} \mathrm{mol}^{-1}$ & $\sigma / \mathrm{mS} \mathrm{cm}^{-1}$ \\
\hline 0.0790 & 0.4646 & 0.0000 & 12.00 \\
\hline 0.0729 & 0.4567 & 0.0000 & 11.94 \\
\hline 0.0656 & 0.4489 & 0.0000 & 11.71 \\
\hline 0.0583 & 0.4425 & 0.0000 & 11.27 \\
\hline 0.0510 & 0.4371 & 0.0000 & 10.64 \\
\hline 0.0438 & 0.4325 & 0.0000 & 9.79 \\
\hline 0.0365 & 0.4284 & 0.0000 & 8.72 \\
\hline 0.0292 & 0.4247 & 0.0000 & 7.43 \\
\hline 0.0219 & 0.4212 & 0.0000 & 5.92 \\
\hline 0.0146 & 0.4180 & 0.0000 & 4.18 \\
\hline 0.0073 & 0.4146 & 0.0000 & 2.21 \\
\hline 0.0000 & 0.0000 & 0.0000 & 0.01 \\
\hline \multicolumn{4}{|c|}{$T=303.15 \mathrm{~K}$} \\
\hline$x_{\mathrm{LiFSI}} / \mathrm{mol} \mathrm{mol}^{-1}$ & $x_{\mathrm{DMC}} / \mathrm{mol} \mathrm{mol}^{-1}$ & $x_{\mathrm{PC}} / \mathrm{mol} \mathrm{mol}^{-1}$ & $\sigma / \mathrm{mS} \mathrm{cm}^{-1}$ \\
\hline
\end{tabular}




\begin{tabular}{|c|c|c|c|}
\hline 0.0835 & 0.4464 & 0.0000 & 13.68 \\
\hline 0.0802 & 0.4420 & 0.0000 & 13.67 \\
\hline 0.0729 & 0.4337 & 0.0000 & 13.50 \\
\hline 0.0656 & 0.4267 & 0.0000 & 13.16 \\
\hline 0.0583 & 0.4207 & 0.0000 & 12.61 \\
\hline 0.0510 & 0.4153 & 0.0000 & 11.85 \\
\hline 0.0438 & 0.4105 & 0.0000 & 10.87 \\
\hline 0.0365 & 0.4059 & 0.0000 & 9.67 \\
\hline 0.0292 & 0.4016 & 0.0000 & 8.22 \\
\hline 0.0219 & 0.3975 & 0.0000 & 6.54 \\
\hline 0.0146 & 0.3934 & 0.0000 & 4.61 \\
\hline 0.0073 & 0.3891 & 0.0000 & 2.44 \\
\hline 0.0000 & 0.0000 & 0.0000 & 0.01 \\
\hline \multicolumn{4}{|c|}{$T=313.15 \mathrm{~K}$} \\
\hline$x_{\text {LiFSI }} / \mathrm{mol} \mathrm{mol}^{-1}$ & $x_{\mathrm{DMC}} / \mathrm{mol} \mathrm{mol}^{-1}$ & $x_{\mathrm{PC}} / \mathrm{mol} \mathrm{mol}^{-1}$ & $\sigma / \mathrm{mS} \mathrm{cm}^{-1}$ \\
\hline 0.0883 & 0.4297 & 0.0000 & 15.46 \\
\hline 0.0875 & 0.4287 & 0.0000 & 15.46 \\
\hline 0.0802 & 0.4201 & 0.0000 & 15.36 \\
\hline 0.0729 & 0.4128 & 0.0000 & 15.09 \\
\hline 0.0656 & 0.4063 & 0.0000 & 14.63 \\
\hline 0.0583 & 0.4004 & 0.0000 & 13.97 \\
\hline 0.0510 & 0.3949 & 0.0000 & 13.09 \\
\hline 0.0438 & 0.3896 & 0.0000 & 11.98 \\
\hline 0.0365 & 0.3845 & 0.0000 & 10.63 \\
\hline 0.0292 & 0.3796 & 0.0000 & 9.03 \\
\hline 0.0219 & 0.3746 & 0.0000 & 7.18 \\
\hline 0.0146 & 0.3697 & 0.0000 & 5.06 \\
\hline 0.0073 & 0.3644 & 0.0000 & 2.67 \\
\hline 0.0000 & 0.0000 & 0.0000 & 0.01 \\
\hline \multicolumn{4}{|c|}{$T=323.15 \mathrm{~K}$} \\
\hline$x_{\text {LiFSI }} / \mathrm{mol} \mathrm{mol}^{-1}$ & $x_{\mathrm{DMC}} / \mathrm{mol} \mathrm{mol}^{-1}$ & $x_{\mathrm{PC}} / \mathrm{mol} \mathrm{mol}^{-1}$ & $\sigma / \mathrm{mS} \mathrm{cm}^{-1}$ \\
\hline 0.0933 & 0.4144 & 0.0000 & 17.33 \\
\hline
\end{tabular}




\begin{tabular}{|c|c|c|c|}
\hline 0.0875 & 0.4078 & 0.0000 & 17.28 \\
\hline 0.0802 & 0.4004 & 0.0000 & 17.08 \\
\hline 0.0729 & 0.3937 & 0.0000 & 16.70 \\
\hline 0.0656 & 0.3874 & 0.0000 & 16.13 \\
\hline 0.0583 & 0.3814 & 0.0000 & 15.35 \\
\hline 0.0510 & 0.3756 & 0.0000 & 14.34 \\
\hline 0.0438 & 0.3698 & 0.0000 & 13.10 \\
\hline 0.0365 & 0.3641 & 0.0000 & 11.61 \\
\hline 0.0292 & 0.3584 & 0.0000 & 9.86 \\
\hline 0.0219 & 0.3527 & 0.0000 & 7.83 \\
\hline 0.0146 & 0.3468 & 0.0000 & 5.52 \\
\hline 0.0073 & 0.3405 & 0.0000 & 2.92 \\
\hline 0.0000 & 0.0000 & 0.0000 & 0.01 \\
\hline \multicolumn{4}{|c|}{$T=333.15 \mathrm{~K}$} \\
\hline$x_{\mathrm{LiFSI}} / \mathrm{mol} \mathrm{mol}^{-1}$ & $x_{\mathrm{DMC}} / \mathrm{mol} \mathrm{mol}^{-1}$ & $x_{\mathrm{PC}} / \mathrm{mol} \mathrm{mol}^{-1}$ & $\sigma / \mathrm{mS} \mathrm{cm}^{-1}$ \\
\hline 0.0989 & 0.4006 & 0.0000 & 19.29 \\
\hline 0.0948 & 0.3963 & 0.0000 & 19.27 \\
\hline 0.0875 & 0.3892 & 0.0000 & 19.12 \\
\hline 0.0802 & 0.3826 & 0.0000 & 18.81 \\
\hline 0.0729 & 0.3762 & 0.0000 & 18.33 \\
\hline 0.0656 & 0.3699 & 0.0000 & 17.65 \\
\hline 0.0583 & 0.3636 & 0.0000 & 16.75 \\
\hline 0.0510 & 0.3574 & 0.0000 & 15.62 \\
\hline 0.0438 & 0.3511 & 0.0000 & 14.25 \\
\hline 0.0365 & 0.3447 & 0.0000 & 12.61 \\
\hline 0.0292 & 0.3382 & 0.0000 & 10.70 \\
\hline 0.0219 & 0.3316 & 0.0000 & 8.50 \\
\hline 0.0146 & 0.3248 & 0.0000 & 6.00 \\
\hline 0.0073 & 0.3174 & 0.0000 & 3.17 \\
\hline 0.0000 & 0.0000 & 0.0000 & 0.02 \\
\hline
\end{tabular}

